\title{
UKURAN DAN BENTUK LENGKUNG GIGI RAHANG BAWAH PADA SUKU MINAHASA
}

\author{
${ }^{1}$ Dwi R. A. Alpiah \\ ${ }^{2}$ P. S. Anindita \\ ${ }^{2}$ Juliatri \\ ${ }^{1}$ Kandidat Skripsi Program Studi Pendidikan Dokter Gigi Fakultas Kedokteran \\ ${ }^{2}$ Program Studi Pendidikan Dokter Gigi Fakultas Kedokteran \\ Universitas Sam Ratulangi Manado \\ Email: adwirenata@yahoo.com
}

\begin{abstract}
Mandibular dental arch size and form are required to establish proper diagnosis and treatment plans in order to achieve maximum stability of treatment outcomes. This study aimed to determine the means of mandimular dental arch size and form in Minahasa ethnic. This study used 25 models of mandibular from Minahasan students at Dentistry Sam Ratulangi University selected by inclusion and exclusion criterion. The models were measured in sagittal (dental arch length) and transversal (dental arch width) direction based on Raberin's method. The result of the dental arch length means of mandibular arch of Minahasan students in sagittal direction L31, L61, and L71 were 5.12, 23.47, and $38.78 \mathrm{~mm}$ consecutively, while the dental arch width in transversal direction L33, L66 and L77 were 26.02, 46.86, and 55.90 $\mathrm{mm}$. The distribution of mandibular dental arch form were mid $36 \%$, narrow $24 \%$, wide $20 \%$, flat $12 \%$, and pointed $8 \%$.
\end{abstract}

Keywords: dental arch length and width, dental arch form, mandibular, Minahasan ethnic

\begin{abstract}
Abstrak: Ukuran dan bentuk lengkung gigi rahang bawah sangat diperlukan dalam menentukan diagnosis dan rencana perawatan yang tepat. Hal ini bertujuan untuk mendapatkan stabilitas hasil perawatan yang maksimal. Tujuan penelitian ini adalah untuk mendapatkan rerata ukuran dan bentuk lengkung gigi rahang bawah pada suku Minahasa.Penelitian ini menggunakan 25 model studi rahang bawah yang diperoleh dari mahasiswa suku Minahasa di PSPDG FK Unsrat yang sesuai dengan kriteria inklusi dan eksklusi yang telah ditentukan. Model studi yang diperoleh diukur dalam arah sagital (panjang) dan transversal (lebar) berdasarkan metode Raberin. Setelah dilakukan pengukuran, diperoleh rerata panjang lengkung gigi rahang bawah mahasiswa suku Minahasa dalam arah sagital yaitu L31, L61 dan L71 berturut-turut 5,12; 23,47; dan 38,786 mm, sedangkan rerata lebar lengkung gigi dalam arah transversal yaitu L33, L66 dan L77 sebagai berikut 26,02; 46,86; dan 55,90 $\mathrm{mm}$. Distribusi bentuk lengkung gigi rahang bawah pada mahasiswa suku Minahasa di PSPDG FK Unsrat ialah mid 36\%, narrow $24 \%$, wide $20 \%$, flat $12 \%$, dan pointed $8 \%$.
\end{abstract}

Kata kunci: panjang dan lebar lengkung gigi, bentuk lengkung gigi, rahang bawah, suku Minahasa

Lengkung gigi terdiri dari rahang atas dan rahang bawah. Lengkung gigi berbeda pada setiap individu karena dipengaruhi oleh lingkungan, nutrisi, genetik, ras dan jenis kelamin. Lengkung gigi merupakan suatu acuan dalam menentukan perawatan ortodonti dentofasial. ${ }^{1}$ Keberhasilan suatu perawatan ortodonti tergantung dari diagnosis dan rencana perawatan yang tepat. Ukuran dan bentuk lengkung gigi merupakan salah satu hal yang sangat penting dalam menentukan diagnosis dan 
rencana perawatan. $^{2}$ Beberapa peneliti menyatakan bahwa kestabilan bentuk dan ukuran lengkung gigi rahang bawah merupakan faktor stabilitas dari hasil perawatan. $^{3}$

Penelitian mengenai bentuk lengkung gigi telah dimulai sejak awal berkembangnya ilmu ortodonti pada tahun 1889 oleh Bonwill. ${ }^{4}$ Sejak saat itu berbagai penelitian dikembangkan untuk memrediksi bentuk lengkung gigi individual.

Rahang bawah merupakan bagian wajah yang mempunyai struktur tulang paling kuat dibandingkan struktur tulang wajah lain dan sangat individual. Setiap perubahan yang terjadi pada lengkung gigi rahang bawah akan memengaruhi lengkung gigi rahang atas bukan sebaliknya. ${ }^{5}$

Beberapa penelitian tentang ukuran dan bentuk lengkung gigi rahang bawah telah dilakukan di Indonesia dengan menggunakan metode Raberin antara lain pengukuran lengkung gigi rahang bawah pada suku Batak, suku Jawa dan suku Papua, serta pada ras Deutro-Melayu. ${ }^{6-7}$

Setiap orang memiliki sifat keturunan yang unik. Lobb, Nakasima dkk, Lundstorm dan McWilliam menyatakan bahwa ada pengaruh genetik yang kuat pada perkembangan bentuk dan hubungan wajah serta rahang. Setiap kelompok etnik cenderung memiliki pola skeletal dan rahang yang berbeda, sehingga ukuran dan bentuk rahang pada suatu kelompok etnik berbeda dengan kelompok etnik lainnya. ${ }^{1,8}$

Sebagian besar penduduk Indonesia didominasi ras Paleomongoloid atau lebih dikenal sebagai ras Melayu yang kemudian dibedakan atas Proto-Melayu dan DeutroMelayu. Suku Minahasa merupakan salah satu suku bangsa Indonesia turunan ras Deutro-Melayu yang berada di ujung Utara pulau Sulawesi. Ukuran dan bentuk lengkung gigi rahang bawah pada suku Minahasa kemungkinan berbeda dengan setiap kelompok suku bangsa di Indonesia lainnya.Berdasarkan hal tersebut, peneliti tertarik melakukan penelitian mengenai ukuran panjang dan lebar serta menentukan bentuk lengkung gigi rahang bawah suku
Minahasa yang belum pernah dilakukan sebelumnya.

\section{BAHAN DAN METODE PENELITIAN}

Penelitian ini merupakan penelitian deskriptif dengan pendekatan potong lintang. Populasi penelitian ini yaitu mahasiswa suku Minahasa angkatan 20112014 di PSPDG FK Unsrat. Pengambilan sampel menggunakan teknik total sampling dan besar sampel penelitian berjumlah 25 orang yang memenuhi kriteria yang telah ditentukan. Pengumpulan data diperoleh dengan melakukan pencetakan rahang bawah pada sampel yang telah mengisi lembar informed consent dan melakukan peminjaman model studi rahang bawah yang tersedia di bagian Ortodonti PSPDG FK Unsrat. Pengukuran panjang dan lebar lengkung gigi model studi rahang bawah mengunakan metode Raberin. Pengukuran panjang diukur melalui arah sagital, masing-masing yaitu L31 yang diukur dari pertengahan gigi insisivus sentralis tegak lurus terhadap garis yang menghubungkan puncak tonjol kaninus, L61 yang diukur dari pertengahan gigi insisivus sentralis tegak lurus terhadap garis yang menghubungkan puncak tonjol mesio-bukal molar pertama kiri dan kanan, dan L71 diukur dari pertengahan gigi insisivus sentralis tegak lurus terhadap garis yang menghubungkanpuncak tonjol disto-bukal molar kedua kiri dan kanan (Gambar 1). ${ }^{9}$

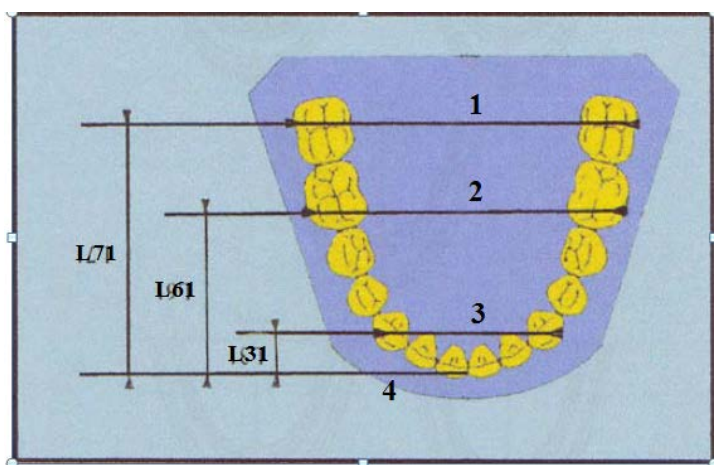

Gambar 1. Pengukuran panjang lengkung gigi menurut Raberin ${ }^{9}$

Keterangan:

1. Garis penghubung puncak tonjol disto-bukal gigi 
M2 kiri dan kanan

2. Garis penghubung puncak tonjol mesio-bukal gigi M1 kiri dan kanan

3. Garis penghubung puncak tonjol gigi $\mathrm{C}$ kiri dan kanan

4. Pertengahan gigi I1 kiri dan kanan

Pengukuran lebar diukur melalui arah transversal, masing-masing yaitu L33 jarak antara tonjol kaninus kiri dan kanan, L66 jarak antara cusp mesio-bukal molar pertama kiri dan kanan, L77 jarak antara cusp disto-bukal molar kedua kiri dan kanan (Gambar 2). ${ }^{9}$

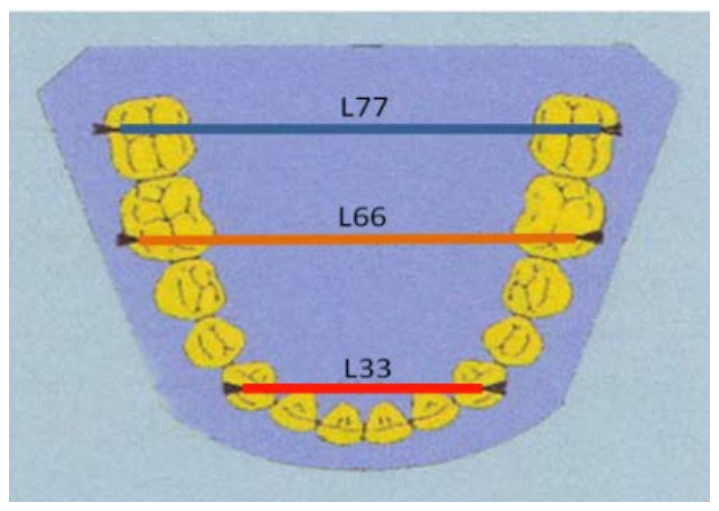

Gambar 2. Pengukuran lebar lengkung gigi menurut Raberin ${ }^{9}$

Keterangan:

- Lebar interkaninus (L33)

- Lebar intermolar pertama (L66)

— Lebar intermolar kedua (L77)

Penentuan bentuk lengkung gigi didapatkan setelah melakukan pengukuran panjang dan lebar, berdasarkan nilai deviasi relatif dari perbandingan L31/L33, L61/L66, L71/L77, L33/L66 dan L61/L71. Bentuk lengkung gigi yang dikategorikan oleh Raberin ada lima bentuk, yaituflat, pointed, mid,wide dan narrow (Gambar 3). ${ }^{9}$

Analisis data dilakukan dengan menghitung rerata ukuran lengkung gigi rahang bawah seluruh sampel, menentukan bentuk lengkung gigi rahang bawah dan menghitung persentase dari masing-masing bentuk lengkung gigi tersebut. Data yang telah diolah dalam program komputerisasi disajikan dalam bentuk Tabel.

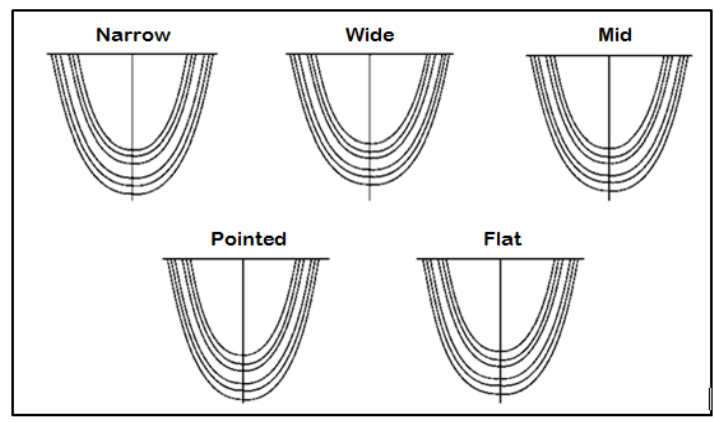

Gambar 3. Klasifikasi bentuk lengkung gigi menurut Raberin ${ }^{9}$

\section{HASIL PENELITIAN}

Pada Tabel 1 ditampilkan rerata ukuran panjang dan lebar lengkung gigi rahang bawah pada sampel penelitian.

Tabel 1. Rerata ukuran lengkung gigi rahang bawah pada suku Minahasa

\begin{tabular}{ccc}
\hline Pengukuran & $\begin{array}{c}\text { Rerata } \\
(\mathrm{mm})\end{array}$ & $\begin{array}{c}\text { Standar Deviasi } \\
(\mathrm{mm})\end{array}$ \\
\hline Panjang & & \\
L31 & 5,12 & 1,23 \\
L61 & 23,47 & 2,09 \\
L71 & 38,78 & 2,43 \\
Lebar & & \\
L33 & 26,20 & 1,98 \\
L66 & 46,86 & 2,45 \\
L77 & 55,90 & 2,88 \\
\hline
\end{tabular}

Hasil pengukuran panjang dan lebar lengkung gigi rahang bawah tersebut kemudian dapat ditentukan bentuk lengkung gigi rahang bawah pada suku Minahasa yang disajikan dalam Tabel 2.

Tabel 2. Distribusi bentuk lengkung gigi rahang bawah pada suku Minahasa

\begin{tabular}{ccc}
\hline Bentuk & N & $\%$ \\
\hline Flat & 3 & 12 \\
Pointed & 2 & 8 \\
Mid & 9 & 36 \\
Wide & 5 & 20 \\
Narrow & 6 & 24 \\
Total & 25 & 100 \\
\hline
\end{tabular}

Hasil penelitian bentuk lengkung gigi rahang bawah mahasiswa suku Minahasa di PSPDG FK Unsrat angkatan 2011-2014 
paling banyak berbentuk mid (36\%), dan yang terkecil ialah pointed (8\%).

Contoh bentuk lengkung gigi rahang bawah pada mahasiswa suku Minahasa di PSPDG FK Unsrat angkatan 2011-2014 dapat dilihat pada Gambar 4.
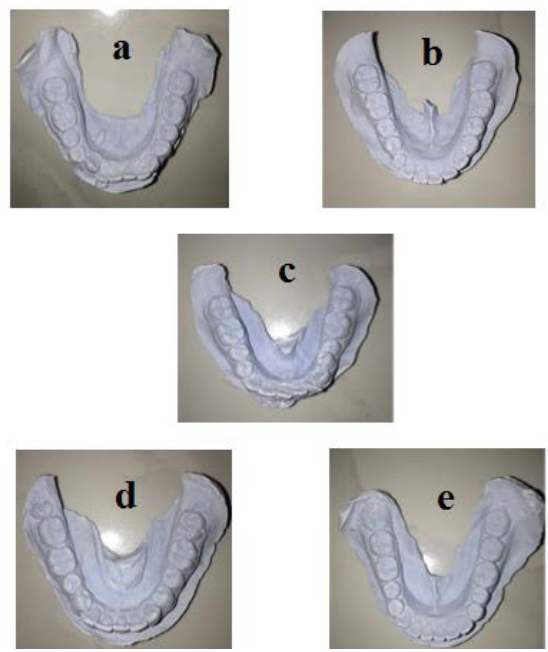

Gambar 4. Contoh bentuk lengkung gigi rahang bawah pada mahasiswa suku Minahasa Keterangan:

$\begin{array}{lll}\mathrm{a}=\text { Flat } & \mathrm{b}=\text { Pointed } & \mathrm{c}=\text { Mid } \\ \mathrm{d}=\text { Wide } & \mathrm{e}=\text { Narrow } & \end{array}$

$\mathrm{e}=$ Narrow

\section{BAHASAN}

Hasil penelitian ini berbeda dengan hasil penelitian Jesika pada tahun 2011 yang melakukan pengukuran lengkung gigi rahang bawah menggunakan metode Raberin pada mahasiswa suku Batak di Fakultas Kedokteran Gigi (FKG) dan Fakultas Teknik (FT) Universitas Sumatera Utara (USU). ${ }^{6}$ Perbedaan hasil pengukuran panjang dan lebar lengkung gigi rahang bawah yaitu masing-masing L31, L61, L71, L33, L66 dan L77 menunjukkan perbedaan angka bervariasi yang tidak terlalu besar (tidak lebih dari $1 \mathrm{~mm}$ ). Sementara itu pengukuran lengkung gigi rahang bawah pada ras Deutro-Melayu yaitu suku Aceh (kecuali Gayo), Jawa, Minangkabau, Bali, Sunda, Palembang dan Makassar di FKG USU yang dilakukan oleh Hasibuan pada tahun 2009, ${ }^{7}$ menunjukkan hasil pengukuran rerata yang lebih kecil dibandingkan dengan suku Minahasa yang juga masih merupakan keturunan ras Deutro-Melayu.
Ukuran panjang dan lebar lengkung gigi rahang bawah tiap individu bervariasi. Beberapa peneliti menyebutkan beberapa faktor yang dapat menyebabkan variasi ukuran lengkung gigi adalah kelompok etnis, jenis kelamin, keturunan, dan lingkungan. ${ }^{10}$ Hal ini dapat terlihat dari hasil penelitian yang telah dilakukan pada suku Minahasa menunjukkan perbedaan yang bervariasi dengan kelompok etnis lain yaitu suku Batak. Hasil penelitian juga menunjukkan adanya variasi dengan penelitian serupa yang dilakukan pada mahasiswa ras Deutro-Melayu di FKG USU, walaupun suku Minahasa juga masih merupakan keturunan dari ras tersebut. Cassidy menyatakan bahwa faktor lingkungan lebih berpengaruh terhadap ukuran dan bentuk lengkung gigi daripada faktor genetik. Hal-hal yang termasuk dalam faktor lingkungan tersebut antara lain lokasi, makanan, kebiasaan oral, fisik dan malnutrisi. Kebiasaan makan makanan dengan tekstur yang lebih halus menyebabkan penggunaan otot pengunyahan dan gigi berkurang, sehingga hal ini berpengaruh pada ukuran rahang bawah menjadi kecil dan rahang atas menjadi sempit. ${ }^{11}$ Kebiasaan oral yang memengaruhi lengkung gigi antara lain menghisap ibu jari atau jari-jari tangan, menghisap dot, bernafas melalui mulut, dan penjuluran lidah. Kebiasaan oral yang akan memengaruhi pada ukuran dan benyuk lengkung gigi tergantung dari frekuensi dan lama durasi melakukan kebiasaan tersebut. $^{12}$ Malnutrisi dapat menimbulkan kelainan pada gigi dan mulut serta dapat memengaruhi pertumbuhan dan perkembangan gigi geligi dan tulang rahang menjadi lambat. ${ }^{11}$

Raberin telah melakukan penelitian untuk menetapkan ukuran dan bentuk lengkung gigi rahang bawah yang ideal dan menyatakan bahwa ada lima bentuk lengkung gigi rahang bawah, yaitu flat, pointed, mid, wide dan narrow. Penentuan bentuk lengkung gigi rahang bawah didapatkan berdasarkan nilai deviasi relatif dari lima perbandingan ukuran panjang dan lebar yaitu masing-masing perbandingan 


\section{L31/L33, L61/L66, L71/L77, L33/L66 dan L61/L71 (Tabel 3). ${ }^{9}$}

Hasil penelitian dari 25 sampel rahang bawah pada mahasiswa suku Minahasa di PSPDG FK Unsrat dikelompokkan menjadi beberapa macam bentuk lengkung gigi rahang bawah (Tabel 2). Bentuk lengkung gigi rahang bawah yang paling banyak yaitu mid (36\%) sedangkan bentuk lengkung gigi rahang bawah yang paling sedikit yaitu pointed (8\%).

Tabel 3. Bentuk lengkung gigi menurut Raberin

\begin{tabular}{|c|c|}
\hline $\begin{array}{l}\text { Bentuk } \\
\text { Lengkung Gigi } \\
\text { Rahang Bawah }\end{array}$ & $\begin{array}{l}\text { Nilai Deviasi Relatif } \\
\text { dari } 5 \text { Perbandingan }\end{array}$ \\
\hline Flat & $\begin{array}{l}\text { L31/L33 }<\text { L61/L66, } \\
\text { L71/L77, } \\
\text { L61/L71 }\end{array}$ \\
\hline Pointed & $\begin{array}{l}\text { L31/L33 > L61/L66, } \\
\text { L71/L77, } \\
\text { L61/L71 }\end{array}$ \\
\hline Mid & $\begin{array}{l}\text { L31/L33, L61/L66, } \\
\text { L71/L77, L33/L66, } \\
\text { L61/L71 hasilnya } \\
\text { tidak ada perbedaan } \\
\text { yang signifikan }\end{array}$ \\
\hline Wide & $\begin{array}{l}\text { L31/L33, L61/L66, } \\
\text { L71/L77 bernilai } \\
\text { positif (+) }\end{array}$ \\
\hline Narrow & $\begin{array}{l}\text { L31/L33, } \\
\text { L71/L77 } \\
\text { negatif (-) }\end{array}$ \\
\hline
\end{tabular}

Bentuk mid didapatkan karena tidak ada perbedaan yang terlalu jauh dari hasil pengukuran panjang dan lebar lengkung gigi, yaitu terdapat keseimbangan antara arah antero-posterior dengan lateral lengkung gigi rahang bawah. Lain halnya dengan bentuk pointed, hal ini dikarenakan hasil pengukuran arah anterior lebih besar daripada arah lateral. ${ }^{12}$

Lavelle dan Olmez menyatakan bahwa kelompok ras yang berbeda akan menunjukkan ukuran dan bentuk lengkung gigi yang bervariasi. ${ }^{13,14}$ Pernyataan tersebut dibuktikan dengan adanya perbedaan antara penelitian Jesika pada mahasiswa suku Batak yang termasuk dalam ras Proto-melayu di FKG dan FT USU paling banyak berbentuk narrow, ${ }^{6}$ sedangkan hasil dari penelitian ini menunjukkan bahwa bentuk lengkung gigi pada mahasiswa suku Minahasa yang termasuk dalam ras Deutro-Melayu di PSPDG FK Unsrat paling banyak berbentuk mid. Variasi bentuk juga tidak hanyak didapat melalui perbedaan kelompok suku namun dalam satu kelompok ras yang sama juga menampilkan variasi perbedaan bentuk seperti hasil penelitian Hasibuan yang menunjukkan bentuk paling banyak pada ras DeutroMelayu di FKG USU adalah wide ${ }^{7}$ sedangkan suku Minahasa yang juga termasuk dalam ras Deutro-Melayu tidak demikian.

Bentuk lengkung gigi menjadi pertimbangan utama bagi para dokter gigi, khususnya dalam memperkirakan perubahan pertumbuhan yang akan datang dan stabilisasi hasil perawatan. ${ }^{9,13}$ Para ortodontis sejak zaman Angle menetapkan satu bentuk lengkung gigi yang ideal sebagai hasil dari perawatan ortodonti. ${ }^{1}$ Namun Raberin dalam penelitiannya menyatakan bahwa bentuk lengkung rahang bawah yang ideal tidak hanya satu macam karena bentuk lengkung yang ideal pada satu individu tidak sama dengan bentuk lengkung individu yang lain. ${ }^{9}$

Adanya variasi ukuran dan bentuk lengkung gigi rahang bawah pada setiap individu merupakan hal yang pasti, sehingga tidak ada satupun bentuk yang ideal yang dapat dijadikan standar untuk menentukan bentuk lengkung gigi individual. Ukuran dan bentuk lengkung gigi perlu dipertimbangkan dalam melakukan rencana perawatan khususnya dalam bidang ortodonti karena ukuran dan bentuk lengkung gigi rahang bawah ideal yang dimiliki setiap individu berbeda-beda satu dengan yang lain.

\section{SIMPULAN}

Berdasarkan hasi penelitian dapat disimpulkan rerata ukuran panjang lengkung gigi rahang bawah pada suku Minahasa yang diukur melalui arah sagital, 
masing-masing L31, L61, L71 yaitu 5,12; 23,47; 38,78 mm, sedangkan lebar lengkung gigi rahang bawah dalam arah transversal, masing-masing L33, L66, L77 yaitu 26,20; 46,86; 55,90 mm.Bentuk lengkung gigi rahang bawah yang paling banyak pada suku Minahasa yaitu mid sedangkan pointed merupakan bentuk paling jarang.

\section{SARAN}

Disarankan bagi para praktisi kedokteran gigi khususnya dalam bidang ortodonti, agar lebih memerhatikan ukuran dan bentuk lengkung gigi mengingat tiap individu memiliki ukuran dan bentuk lengkung gigi yang bervariasi. Hal ini dikarenakan ukuran dan bentuk lengkung gigi merupakan salah satu hal yang penting dalam menentukan stabilitas suatu perawatan ortodonti.

\section{DAFTAR PUSTAKA}

1. Foster TD. Buku ajar ortodonsi (Edisi 3). Alih bahasa: Lilian Yuwono. Jakarta: EGC, 1997; p. 16-7,47,95.

2. Tajik I, Mushtaq N, Khan M. Arch forms among different angle classifications a - study. Pakistan Oral \& Dental Journal 2011;31(1):92-5.

3. Nojima $K$, McLaughlin RP, Isshiki $Y$, Sinclair PM. A comparative study of caucasian and japanese mandibuar clinical arch forms. J Angle Orthod 2001;71(3):195-200.

4. Conti MF, Filho MV, Vedovello SAS, Valdrigi HC, Kuramae $M$. Longitudinal evaluation of dental arches individualized by the WALA ridge method. Dental Press J Orthod 2011;16(2):65-74.

5. Solekah S.Pengaruh perawatan ortodontik cekat teknik Begg terhadap bentuk dan lebar lengkung gigi berdasarkan titik pengukuran WALA ridge [Tesis] Yogyakarta: Univeritas Gadjah Mada; 2014. p. 3.

6. Jesika. Ukuran dan bentuk lengkung gigi rahang bawah pada mahasiswa suku Batak Fakultas Kedoktean Gigi dan Teknik USU [Skripsi] Medan: Universitas Sumatera Utara; 2009. p. 4-6, 22-3.

7. Hasibuan MK. Ukuran dan bentuk lengkung gigi rahang bawah pada mahasiswa FKG-USU ras DeutroMelayu [Skripsi] Medan: Universitas Sumatera Utara; 2009. p. 5-14, 26-7.

8. Lobb KW. Craniofacial morphology and acclusal variation in monozygous and dizygous twins. J Angle Orthod 1987; 57(3):219-33.

9. Raberin M, Laumon B, Martin JL, Brunner F. Dimension and form of dental arches in with normal occlusion. Am J Orthod Dentofac \& Orthod 1993;104:67-72.

10.Sylvia, Mieke M. Variasi normal ukuran gigi rahang dan wajah penduduk pulau Flores dan Timor Nusa Tenggara Timur (suatu tinjauan antropometris). FIKG IV 1993;2(4): 460-1.

11.Cassidy KM, Edward F, Elizabeth A, Robert G. Genetic influence on dental arch form. J Angle Orthod 1998;68(5):445-54.

12.Aznar T, Galan AF, Marin I, Dominguez A. Dental arch diameters and relationships to oral habits. J Angel Orthod 2006;76(3):441-5.

13.Olmez S, Dogan S. Comparison of the arch form and dimensions in various maloccusions of the Turkish population. Open Journal of Stomatology 2011;1:158-64.

14.Lavelle CLB, Foster TD, Flinn RM. Dental arches in various ethnic groups. J Angle Orthod 1971;41(4): 293-9. 